rối loạn lo âu và trầm cảm đã được tìm thấy ở $40,71 \%$ và $32,14 \%$ bệnh nhân nữ [7]. Dường như có sự khác biệt giữa nam và nữ về tỉ lệ lo lắng và trầm cảm ở các bệnh nhân đau thắt lưng mạn tính do thoái hóa. Sự khác biệt này có thể là do sự khác biệt về ngướng chịu đựng đau và khả năng chịu đựng của tình trạng tâmm lý ở nữ giới thấp hơn so với nam giới. Bằng chứng sinh học cho thấy rằng phụ nữ và đàn ông có thể có mức chịu dựng đau lưng mạn tính khác nhau. Mô hình sinh học dự đoán rằng phụ nữ dễ bị đau hơn và sẽ trải qua nhiều rối loạn chức năng tâm lý hơn do khả năng chịu đựng đau và sự thích ứng kém hơn so với nam giới. Bằng chứng xã hội tâm lý cho thấy rằng phụ nữ thường khó khăn khi đối phó với tình trạng đau thắt lưng mạn tính [8].

\section{KẾT LUẬN}

Nghiên cứu đã chỉ ra một cách rõ ràng rằng trong điều trị cho những bệnh nhân bị đau thắt lưng mạn tính do thoái hóa cột sống, các yếu tố tâm lý của bệnh nhân cũng có vai trò quan trọng, bởi lẽ những bệnh nhân bị thắt lưng mạn tính do thoái hóa cột sống có nguy cơ gặp phải rối loạn lo âu và trầm cảm. Ở những bệnh nhân này, tình trạng bệnh trở nên phức tạp do có thêm các dấu hiệu rối loạn về tâm lý như lo lắng và trầm cảm vì vậy cần được điều trị bởi liệu pháp thích hợp. Ngoài ra, một điều quan trọng trong điều trị bệnh nhân đau lưng mạn tinh đó là giới tình, cần hiểu rằng có sự khác biệt về tâm lý giữa nam và nữ và cách họ phản ứng với tình trạng đau lưng.

\section{TÀI LIÊU THAM KHẢO}

1. Croft P, Macfarlane G, Papageorgiou A, and et al, "Outcome of Low back pain general practice: a prospective study," BMJ, vol. 316, no. 2, pp. 1356-1359, 1998.

2. Rush. AJ, Polatin. $\mathbf{P}$, and Garchel. RJ., "Depression and chronic low back pain. Establishing priorities in treatment," Spine (Phila Pa 1976), vol. 25, pp. 2566-2571, 2000.

3. Snaith RP and Zigmond AS, "The hospital anxiety and depression scale," Br. Med. J. (Clin. Res. Ed)., vol. 292, no. 6516, p. 344, Feb. 1986, doi: 10.1136/bmj.292.6516.344.

4. Polatin. PB, Kinney. RK, and Gatchel. RJ, "Psychiatric illness and chronic low back pain," Spine (Phila Pa 1976), vol. 18, pp. 66-71, 1993.

5. Sathya P, "Prevalence of depression; Anxiety and stress in patients with Mechanical Low Back Pain .," Int J Ther. Rehab Res., vol. 4, no. 4, pp. 67-72., 2015.

6. Herrman $\mathbf{C}_{\text {., }}$ "International experiences with the Hospital Anxiety and Depression Scale. A review of validation data and clinical results.," J. Psychosom Res, vol. 42, pp. 17-41, 1997.

7. Sagheer M.A, "Association between Chronic Low Back Pain, anxiety and depression in patients at a tertiary care centre.," J Pak Med Assoc ., vol. 63, no. 6, pp. 213-218, 2013.

8. Sheffer, "Sex differences in presentation of Chronic Low Back Pain.," in Psychology of Women Quarterly, Printed in ÚSA: Blackwell Publishing., 2002, pp. 329-340.

\title{
ĐẶC ĐIỂM LÂM SÀNG TRÊN BỆNH NHÂN TRỨNG CÁ THÔNG THƯỜNG ĐẾN KHÁM VÀ ĐÎ̀̃U TRI TẠI BỆNH VIỆN ĐẠI HỌC Y DƯợC CẦN THO' NĂM 2018-2019
}

\author{
Trịnh Tiến Thành*, Huỳnh Văn Bá*, Trần Đăng Quyết**
}

\section{TÓM TẮT}

Mục tiêu: Mô tả một số đặc điểm lâm sàng trong bệnh trứng cá thông thường. Đối tượng và phương pháp: Mô̂ tả cắt ngang 241 trường hợp bệnh nhân được chẩn đoán trứng cá thông thường tại Phòng khám Da liễu - Bệnh viện Đại học Y Dược Cần Thơ trong thời gian từ 10/2018 đến 8/2019. Kết quả: Bênh nhân là học sinh-sinh viên chiếm tỉ lệ ca onhất $(50,6 \%)$. Vị trí tổn thương ở mặt chiếm tỉ lệ cao nhất

*Bệnh viện Đại họ Y Dược Cần Thơ

**Bênh viện Quân y 103

Chịu trách nhiệm chính: Huỳnh Văn Bá

Email: bs.ba_fob@yahoo.com.vn

Ngày nhận bài: 3/5/2021

Ngày phản biện khoa học: 22/5/2021

Ngày duyệt bài: 2/7/2021
$(99,2 \%)$, các vùng da khác tỉ lệ thấp hơn như lưng $(45,2 \%)$, ngực $(17,7 \%)$. Tổn thương nhân trứng cá hay gặp nhất $(96,3 \%)$, tiếp đến là sẩn viêm $(93,4 \%)$, mụn mủ $(89,6 \%)$, các tổn thương cục, giãn mạch, sẹo lồi, seo lõ̃m chiếm tỷ lê íthấp hơn. Tất cả các bênh nhân tham gia nghiên cứu đều có biểu hiện da nhờn ở các mức đô khác nhau. Kết luân: Đa số bênh nhân là học sinh-sinh viên. Vị trí hay gặp nhất là ở vùng mặt. Dang tổn thương hay gặp nhất là sẩn và nhân trứng cá. Tất cả các bệnh nhân tham gia nghiên cứu đều có biểu hiện da nhờn.

Tư khóa: Bệnh trứng cá, đặc điểm lâm sàng.

\section{SUMMARY \\ CLINICAL CHARACTERISTICS ON PATIENT \\ WITH ACNE VULGARIS TREATED ATCAN \\ THO UNIVERSITY OF MEDICINE AND PHARMACYIN 2018-2019}


Objective: Describe some clinical characteristics in acne vulgaris. Subjects and method: Crosssectional descriptions. Twohundreds and forty-one cases of patients diagnosed with acne vulgaris at Dermatology Clinic - Can Tho University Of Medicine And Pharmacy in the period from 10/2018 to 8/2019. Results: Patient is student with the highest rate $(50,6 \%)$. The position with the highest rate of lesions is face area $(99,2 \%)$, the other skin areas has lower rate are back $(45,2 \%)$, chest $(17,7 \%)$. The most common lesion is comedones $(96,3 \%)$, followed by papules $(93,4 \%)$, pustules $(89,6 \%)$, cysts, flushing, keloids, atrophic scars accounted for lower rates. All patients in the study have oily skin in different levels. Conclusion: Most patients are students. The most common position is in the face area. The most common lesion is papules and comedone. All patients in the study have oily skin.

Keywords: Acne, clinical characteristics.

\section{I. ĐĂT VẤN ĐỀ}

Bệnh trứng cá là một bệnh rất thường gặp, có thể khởi phát từ thời niên thiếu, đến tuổi trưởng thành, có khi kéo dài đến tuổi 35- 44 [1]. Bệnh thường không ảnh hưởng nghiêm trọng đến tính mạng. Tuy nhiên, sự tồn tại của tổn thương hay sẹo trên da, nhất là vùng mặt, làm giảm tính thẩm mỹ, ảnh hưởng rất lớn đển chất lượng cuộc sống.

Hiểu rõ về đặc điểm lâm sàng cùn những yếu tố liên quan đến bệnh sinh mụn trong từng độ tuổi là rất cần thiết cho các bác sĩ trong khi tiếp cận điều trị nhóm bênh nhân này. Với mong muốn làm rõ thêm về biểu hiện lâm sàng của bệnh trứng cá thông thường tại Việt Nam, chúng tôi tiến hành đề tài nghiên cứu đề tài này nhằm mục tiêu: Mô tả đặc điểm lâm sàng bệnh nhân trứng cá thông thường đến khám tại Bệnhviện Đai hoc Y Dược Cần Thó.

\section{II. ĐỐI TƯỢNG VÀ PHƯƠNG PHÁP NGHIÊN CỨU}

1. Đối tượng nghiên cứu. Bệnh nhân trứng cá thông thường đến khám và điều trị tại phòng khám Da liễu - Khoa Khám bệnh - Bệnh viện Đại học Y Dược Cần Thơ.

Tiêu chuẩn chẩn đoán:

- Chẩn đoán xác định bệnh trứng cá thông thường: chủ yếu dựa vào lâm sàng [2]:

+ Vị trí tổn thương: vùng mă̆t, ngực, lưng

+ Tổn thương cơ bản: Tổn thương không viêm: nhân trứng cá đầu trắng, đâu đen, tổn thương viêm: sẩn viêm có nhân trứng cá ở giữa, mụn mủ, viêm tấy, nang bọc.

- Chẩn đoán mức độ bệnh: Theo phân loại Karen McCoy-2008 [3]:

+ Mức độ nhẹ: <20 tổn thương không viêm, hoặc <15 tổn thương viêm, hoặc tổng số tổn thương $<30$.
+ Mức độ vừa: $\leq 5$ nang/cục hoặc 20-100 tổn thương không viêm, hoặc 15-50 tổn thương viêm, hoặc tổng số tổn thương 30-125.

+ Mức độ nặng: >5 nang/ cục, hoặc>100 tổn thương không viêm, hoặc $>50$ tổn thương viêm, hoặc tổng số tổn thương $>125$.

Tiêu chuẩn chọn bệnh nhân: Tất cả bệnh nhân trứng cá thông thường đến khám và điều trị tại phòng khám Da liễu - Khoa Khám bệnh bệnh viện Đạihọc $Y$ Dược Cần Thơtừ tháng 10/2018 đến tháng 8/2019.

\section{Tiêu chuẩn loại trừ:}

- Bệnh nhân khổng đồng ý tham gia nghiên cứu

- Bệnh nhân mắc các thể khác của bệnh trứng cá

\section{Phương pháp nghiên cứu}

Thiết kế nghiên cứu: Mô tả cắt ngang.

Cỡ mẫu nghiên cứu: Mẫu thuân tiện - tất cả bệnh nhân trứng cá đến khám và điều trị tại Phòng khám Da liễu - Bệnh viện Đại học Y Dược Cần Thơ từ 10/2018-8/2019.

\section{Các bước tiến hành:}

- Tuyển chọn bệnh nhân đủ tiêu chuẩn vào mẫu nghiên cứu.

- Đăng ký hồ sơ: các chỉ tiêu cần cho nghiên cứu: tuổi, giới, nghề....

- Khám lâm sàng: chẩn đoán bệnh, đánh giá mức độ bệnh.

Các chỉ tiêu đánh giá: Các chỉ tiêu theo dõi về đặc điểm lâm sàng:

- Tuổi (tính theo năm), giới, nghề nghiệp, địa dư, thời gian mắc bệnh (tính theo tháng),

- Vị trí tổn thương, các loại tổn thương, mức độ bệnh, triệu chứng cơ năng, mức độ da nhờn

Xử lý số liệu: Sử dụng phần mềm SPSS 22.0.

\section{Địa điểm và thời gian nghiên cứu:}

- Địa điểm: Phòng khám Da liễu-Bệnh viện Đại học Y Dược Cần Thơ.

- Thờigian: 10/2018 - 08/2019.

\section{KẾT QUẢ NGHIÊN CỨU}

Trong thời gian nghiên cứu, chúng tôi khảo sát được 241 bệnh nhân trứng cá thông thường.

Bảng 1. Phần bố theo giới $(n=241)$

\begin{tabular}{|c|c|c|c|}
\hline Giới tính & $\mathbf{n}$ & Tỷ lệ \% & p \\
\cline { 1 - 3 } Nam & 87 & 36,1 & \multirow{2}{*}{$\mathrm{p}<0,05$} \\
\cline { 1 - 3 } Nữ & 154 & 63,9 & \\
\cline { 1 - 3 } Tống & 241 & 100 & \\
\hline
\end{tabular}

Nhânn xét: Trong dân số mầu của chúng tôi, số bệnh nhân nữ chiếm gần gấp đôi so với nam giới $(63,9 \%$ so với $36,1 \%)$, sự khác biệt có ý nghĩa thống kê với $p<0,05$. 
Bảng 2. Phân bố theo thời gian mắc bệnh $(n=241)$

\begin{tabular}{|c|c|c|}
\hline Thời gian măc bệnh & $\mathbf{n}$ & Tỷ lệ $\%$ \\
\hline < 6 tháng & 47 & 19,5 \\
\hline 6 tháng -1 năm & 75 & 31,1 \\
\hline$>1$ năm & 119 & 49,4 \\
\hline Tống & $\mathbf{2 4 1}$ & $\mathbf{1 0 0}$ \\
\hline
\end{tabular}

Nhận xét: Bệnh nhân có thời gian mắc bệnh $>1$ năm chiếm tỷ lệ cao nhất 49,4\%, tiếp đến là bệnh nhân có thời gian mắc bênh từ 6 tháng -1 nằm với $31,1 \%$ và thấp nhất là mắc bệnh dưới 6 tháng với 19,5\%. Hầu hết bệnh nhân mắc bệnh trên 6 tháng (chiếm tỷ lệ 80,6\%).

Bảng 3. Phân bố theo nghề nghiệp $(n=241)$

\begin{tabular}{|c|c|c|}
\hline Nghề nghiệp & $\mathbf{n}$ & Tỷ lệ $\%$ \\
\hline Học sinh-sinh viên & 122 & 50,6 \\
\hline Cán bộ văn phòng & 56 & 23,2 \\
\hline Nghề khác & 63 & 26,1 \\
\hline Tống & $\mathbf{2 4 1}$ & $\mathbf{1 0 0}$ \\
\hline
\end{tabular}

Nhận xét: Học sinh-sinh viên mắc trứng cá thông thường chiếm tỷ lệ cao nhất với $50,6 \%$, tiếp đến là nhóm các nghề khác với $31,4 \%$ và thấp nhất là nhóm cán bộ văn phòngvới $24,0 \%$.

Bảng 4. Phân bố theo vị trí địa lý $(n=241)$

\begin{tabular}{|c|c|c|}
\hline Nờ sống & $\mathbf{n}$ & Tỷ lệ \% \\
\hline Thànhphố & 192 & 79,9 \\
\hline Nôngthôn & 49 & 20,3 \\
\hline Tống & $\mathbf{2 4 1}$ & $\mathbf{1 0 0 \%}$ \\
\hline
\end{tabular}

Nhân xét: đa số bênh nhân mắc trứng cá thông thường sống ở thành thị với tỷ lệ $79,9 \%$, cao hơn so với sônng ở nông thôn với 20,3\%.

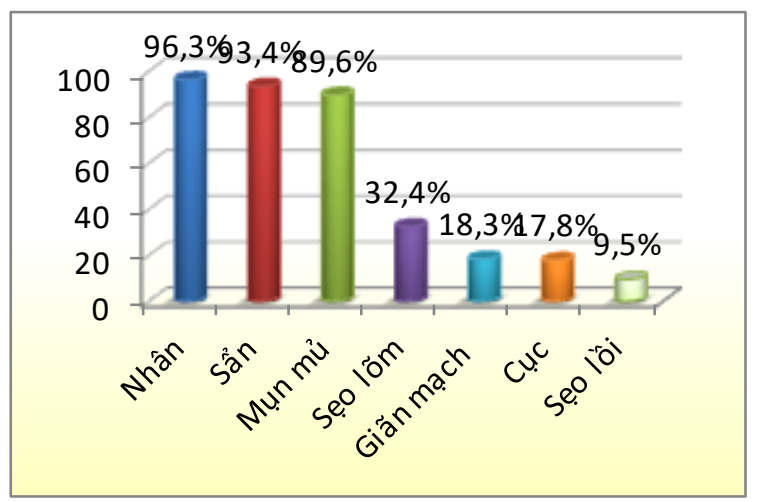

Biểu đồ 1. Phân bố về dạng tổn thương

Nhận xét: Thương tổn chiếm tỷ lệ cao nhất là nhân, sẩn và thương tổn mụn mủ với tỷ lệ lần lượt là $96,3 \%, 93,4 \%$ và $89,6 \%$ : thấp nhất là thương tổn sẹo lồi với tỷ lệ 9,5\%.

Bảng 5. Phân bố theo vị trí tôn thương $(n=241)$

\begin{tabular}{|c|c|c|}
\hline Vị trí & $\mathbf{n}$ & Tỷ lệ \% \\
\hline Mặt & $\mathbf{2 3 9}$ & $\mathbf{9 9 , 2}$ \\
\hline Lưng & $\mathbf{5 9}$ & $\mathbf{4 5 , 2}$ \\
\hline
\end{tabular}

\begin{tabular}{|c|c|c|}
\hline Ngực & 43 & 17,7 \\
\hline Nơi khác (cố, vai...) & 36 & 15,3 \\
\hline
\end{tabular}

Nhận xét: Vị trí chiếm tỷ lệ cao nhất là mặt $99,2 \%$ tiếp đến là lưng $45,2 \%$, ngực $17,7 \%$ và thấp nhất là các vị trị khác 15,3\%.

Bảng 6. Liên quan giữa mức độ da nhờn với mức độ bệnh $(n=241)$

\begin{tabular}{|c|c|c|c|c|}
\hline $\begin{array}{c}\text { Mức độ bệnh } \\
\text { Mức độ da nhờn }\end{array}$ & Nhe & Vừa & Nặng & $\%$ \\
\hline Da nhờnnhẹ & 30 & 24 & 2 & 23,2 \\
\hline Da nhờn vừa & 16 & 72 & 19 & 44,4 \\
\hline Da rấtnhờn & 2 & 34 & 42 & 32,4 \\
\hline
\end{tabular}

Nhận xét: Tất cả các bệnh nhân tham gia nghiên cứu đều có biểu hiện da nhờn ở các mức độ khác nhau: có 23,2\% biểu hiện da nhờn nhẹ, $44,4 \%$ có biểu hiện da nhờn vừa và $32,4 \%$ có biểu hiện da rất nhờn.

\section{BÀN LUẬN}

- Giới: Nghiên cứu của chúng tôi tiến hành trên 421 bênh nhân mắc trứng cá thông thường khám và điều trị tại bệnh viện trường Đại Học Y Dược Cần Thơ, trong đó có 154 nữ và 87 nam với tỷ lệ lần lượt là $63,9 \%$ và $36,1 \%$. Sự khác biệt giới tính này có ý nghĩa thống kê với $p>0,05$. Kết quả này phù hợp với nghiên cứu của tác giả Huỳnh Văn Bá: tỷ lệ nữ giới mắc bệnh trứng cá chiếm $65 \%$. Nghiên cứu của tác giả Đặng Văn $\mathrm{Em}$ và Nguyễn Thị Minh Hồng cũng cho kết quả tương tự [4], [5].

- Thời gian mắc bệnh: Kết quả nghiên cứu của chúng tôi phù hợp với nghiên cứu của Nguyễn Thị Thanh Nhàn: tuổi bệnh trứng cá phần lớn $>1$ năm. Điều này có thể là do sự thiếu hiểu biết về bệnh nên đa số các bệnh nhân thường chủ quan, cho rằng trứng cá thường tự khỏi và là một bệnh nhẹ, chưa đến mức cần phải đi khám bệnh. Mặt khác là liên quan đến vấn đề kinh tế, vì mỗi lần đi khám bệnh là phải tỗn kém, mất thời gian gây ảnh hưởng đến công việc hàng ngày. Do đó bệnh nhân thường cố hạn chế đi khám bệnh cho tới lúc bệnh nặng lên hoặc có điều kiện về thời gian và tiền bạc thì mới đi khám. Hơn nữa khi bệnh còn ở mức độ nhẹ thì ít gây ảnh hưởng đến tâm lý của người bệnh và các bệnh nhân nam thường ít để ý đến bệnh tật hơn các bệnh nhân nữ; nên thường sau một thời gian khá lâu, có thể tới một vài năm, các bệnh nhân mới đi khám bệnh. Điều này cũng chứng tỏ rằng trứng cá nếu không được điều trị hoặc điều trị không đúng sẽ có tiến triển dai dẳng, mạn tính.

- Nghề nghiệp: Trong nghiên cứu của chúng tôi, học sinh-sinh viên mắc trứng cá thông thường chiếm tỷ lệ cao nhất với $50,6 \%$, tiếp đến 
là nhóm các nghề khác với $26,1 \%$ và thấp nhất là nhóm cán bộ văn phòng với $23,2 \%$. Kết quả này phù hợp với nghiên cứu của Nguyễn Thị Minh Hồng với tỷ lệ học sinh-sinh viên là $55,6 \%$, cán bô công chức là $15,2 \%$ và các nghề khác là 29,2\%[5]; Nguyễn Thị Huyền với học sinh-sinh viên là $64,9 \%$, cán bộ là $9,5 \%$ và các nghề khác là $25,6 \%$ [6].

Bệnh trứng cá là bệnh rất hay gặp ở lứa tuổi tử $12-20$ với tỷ lệ $80-90 \%$. Học sinh-sinh viên là những người trẻ tuổi nằm trong độ tuổi này, bệnh trứng cá lại thường biểu hiện ở mặt gây ảnh hưởng đến tâm lý rất nhiều, nhất là lứa tuổi mới lớn vì thế lứa tuổi này thường đi khám hơn.

- Vị trí địa lý: Đa số bệnh nhân mắc trứng cá thông thường sống ở thành thị với tỷ lệ $79,9 \%$, cao hơn so với sống ở nông thôn với $20,3 \%$. Điều này được giải thích là do Bệnh viện Đại học Y DượcCầnThơ là bệnh viện tuyến trên với chất lượng khám bệnh và điều trị rất tốt. Hơn nữa, những người sống ở thành thị có nhiêu điều kiện để tiếp cận khám chữa bệnh; còn những người sống ở nông thôn còn gặp khó khăn về chi phí, phương tiện đi lại hoặc có thể ho không có sự quan tâm đáng kể đối với trứng cá nên tỷ lệ đến khám ít hơn nhiều.

- Vị trí tổn thương: Theo phân tích của chúng tôi, vị trí mọc trứng cá nhiều nhất là mặt $99,2 \%$ tiếp đến là lưng 45,2\%, ngực 17,7\% và thấp nhất là các vị trị khác 15,3\%.

Tuyến bã có vai trò quan trọng trong cơ chế hình thành bệnh trứng cá. Về nguyên tắc ở đâu có tuyến bã ở đây có nguy cơ bị bệnh trứng cá, vùng nào có mật độ tuyến bã cao sẽ có nguy cơ mắc trứng cá hợn những vùng có mật độ tuyến bã thấp. Da vùng mặt có số lượng tể bào tuyến bã nhiều nhất, tế bào tuyến bã lại có thể tích lớn hơn, tuyến bã phát triển gấp 5 lần ở các nơi khác Đó là lý do tại sao trứng cá hay mọc ở mặt ngực lưng so với vị trí khác. Tuyến bã ở những vùng da khác nhau đáp ứng với nội tiết tố khác nhau. Tuyến bã ở chi dưới đáp ứng với androgen rất thấp hoă̆c không đáp ứng. Trong khi đó ở mặt tuyến bẵ lại đáp ứng với androgen rất manh. Chính vì vây nên trứng cá hay mọc nhất ở mặt (2 gò má, trán, xung quanh miệng), ngực và lưng.

- Các loại tổn thương: Theo ghi nhận của chúng tôi, thương tổn chiếm tỷ lệ cao nhất là nhân với tỳ lệ 96,3\%, tiếp đến là sẩn và thương tổn mụn mủ với tỷ lệ lần lượt là $93,4 \%$ và $89,6 \%$ : thấp nhất là thương tổn sẹo lồi với tỷ lệ $9,5 \%$. Nhiêu nghiên cứu trong nước với cùng đặc điểm dân số cũng cho kết quả tương tự với thương tổn nhâ, sẩn và mụn mủ chiếm đa số: trong nghiên cứu của Vũ Văn Tiến thương tổn sẩn chiếm $75,4 \%$, nhân đầu trắng $71,2 \%$, nhân đầu đen $67 \%$ [7]; theo Nguyễn Thị Minh Hồng, tỷ lệ sẩn $100 \%$, nhân đầu trắng $98,2 \%$, mụn mủ $96,8 \%$, nhân đầu đen $81,6 \%[5]$; còn trong nghiên cứu của Nguyễn Thị Thanh Nhàn, nhân trứng cá chiếm $84,9 \%$, sẩn $78,1 \%$, mun mủ $35,9 \%$, các thương tổn khác chiếm tỷ lệ thấp hơn.

- Mức độ da nhờn: Kết quả phân tích của chúng tôi cho thấy tất cả các bệnh nhân tham gia nghiên cứu đều có biểu hiện da nhờn ở các mức độ khác nhau: có $23,2 \%$ biểu hiện da nhờn ít, $44,4 \%$ có biểu hiện da nhờn mức độ vừa và $32,4 \%$ có biểu hiện da nhờn nhiều. Trong sinh bênh hoc TCTT mặc dù các tuyến bã tiết chất bã để giữ ẩm cho da và góp phần duy trì đô $\mathrm{pH}$, tuy nhiên tăng tiết chất bã là một yếu tố thuận lợi để hình thành thương tổn trứng cá, tăng tiết chất bã làm da nhờn.

\section{KẾT LUẬN}

- Tỷ lệ nữ bị bệnh là 63,9\%, nam là36,1\%.

- Nghề nghiệp chiếm tỷ lệ cao nhất là sinh viên-học sinh chiếm 50,6\%.

- Đa số bệnh nhân sống ở thành thị với tỷ lệ $79,9 \%$.

- Vị trí hay gặp nhất là mặt 99,2\%.

- Tổn thương cơ bản gặp nhiếu nhất là nhân trứng cá $96,3 \%$, sẩn viêm $93,4 \%$, mụn mủ $89,6 \%$

- Tất cả các bệnh nhân tham gia nghiên cứu đều có biểu hiện da nhờn ở các mức độ khác nhau.

\section{TÀI LIÊU THAM KHẢO}

1. Võ Nguyễn Thúy Anh N. T. T. (2009), Đặc điểm lâm sàng và các yếu tố liên quan đến mụn trứng cá ở phụ nữ trưởng thành, Hội nghị khoà học kỹ thuật da liểu khu vực các tỉnh thành phía Nam, Bênh viên Da liễu thành phố Hồ Chí Minh: 28.

2. Bùi Khánh Duy (2008), Trứng cá (acne), Bài giảng bệnh da và hoa liêu, Bộ môn Da liếu, Học viện Quấn y: 188 .

3. Kären McCoy (2008), Acne and related disorder, The Merck Manuals Medical Library.

4. Đăng Văn Em (2006), Kinh nghiềm điều trị bênh trứng cá thông thường bằng 2 phác đồ dùng thuốc có kết hợp Flagyl và không có Flagyl, Y học thực hành, 5(544): 102-103.

5. Nguyễn Thị Minh Hồng (2008), Nghiên cứu đặc điểm lâm sàng và đánh giá hiệu quả điêuu trị bênh trứng cá thông thường bằng Vitamin $a$ acid tại Viện Da Liễu Quốc Gia, Đại học Y Hà Nội.

6. Nguyễn Thị Huyên (2010), Đánh giá hiệu quả điêuu bệnh trứng cá thông thường ở phụ nữ bằng Diane 35, Đai học Y Hà Nô̂i.

7. Vũ Văn Tiến(2002), Tình hình đặc điểm lâm sàng và lượng 17-cetosteroid trong nưởc tiểu bệnh nhân trứng cá thông thường nam giới, Học viện Quân Y. 